\title{
TALKING POINTS
}

\section{The robustness of the London Health Planning Consortium model}

\author{
JOHN CHARLTON
}

The reports from the London Health Planning Consortium (LHPC) Towards a Balance and Acute Hospital Services in London $^{2}$ advocate a reduction in the number of acute beds in London hospitals by 1988. Compared with 1977 "reductions of some 2300 beds $(23 \%)$ are indicated in the teaching health districts." A reduction in the non-teaching districts is also proposed, giving a net reduction in the total number of acute beds in the Thames regions of about $11 \%$. These bed reductions are based on assumptions about future populations, patient flows, hospital admission rates, and average durations of inpatient stay. Much of the data used by the LHPC in its calculations of future bed provision in London are open to questions that cast doubt on their reliability. When there is uncertainty about the quality of data that are available for planning it is best to employ a robust approach-that is, one in which plans are not unduly sensitive to the unreliability of the data. ${ }^{3}$

The data used in the methodology include projected 1988 populations, 1977 Hospital Activity Analysis (HAA) data as an estimate for 1988 population flows, projected shorter durations of stay, and lower hospital admission rates (based on 1962-75 Hospital Inpatient Enquiry (HIPE) data) and retrospective mortality data (1974-6) weighted by utilisation (1975 HIPE) as an indicator of the future level of morbidity. The projections of bed requirements for 1988 are made at district level and clearly stated in terms of numbers of beds required for each specialty.

The DHSS has provided us with projected bed requirements based on alternative population projections, using the LHPC model. The South-east Thames Regional Health Authority has also explored the effects of varying some of the other assumptions one at a time. Though the other assumptions make appreciable differences for some districts I have concentrated on discussing the effects of population projections for which plausible alternatives have been suggested. It should not be overlooked, however, that data on hospital use, particularly HAA, HIPE, and $\mathrm{SH} 3$ forms (statistical returns for the hospital service), have been found to be of questionable reliability. ${ }^{5}$ One of the central LHPC assumptions is that the population of Inner London will decline by $12.5 \%$ between 1977 and 1988, while that of London as a whole will decline by $8 \%$ over that period. These assumptions are based on the Office of Population Censuses and Surveys (OPCS) mid-1977-based projections, which in turn are based on the 1971 census now nine years out of date. We will not have accurate population data until 1982, when the results of the 1981 census begin to become available. Population projections are based on assumptions about future mortality, fertility, and migration. Of these three guesses, migration is the factor subject to the greatest degree of error. The OPCS emphasises that there is controversy and uncertainty about the assumptions on which the projections are based, particularly the migration assumptions, ${ }^{6}$ the uncertainty being greater for smaller areas, where migration is a major factor. Population change through migration may take place at any age and is also affected by national and local government policies.

Department of Community Medicine, St Thomas's Hospital Medical School, London SE1 7EH

JOHN CHARLTON, MSC, lecturer in medical statistics
The Greater London Council (GLC) has calculated that if OPCS's mid-1977-based projections were to apply, using the Department of the Environment's household projection based on the OPCS projection, together with the 1979 Housing Investment Programme returns from each borough, $8 \%$ of all dwellings in London would be vacant by 1986 . The GLC produces its own set of population projections, based on alternative migration and fertility assumptions, which take account of housing investment plans that OPCS's projections do not. The GLC projections also attempt to take into account local gross migration by age structure ("bottom up"), whereas the OPCS's method is to adjust 1971 census data of net migration age structure to meet national and regional control totals ("top down"). Table I compares OPCS and GLC population estimates for 1977 and projections for $1988 .^{7}$ The figure shows these differences graphically.
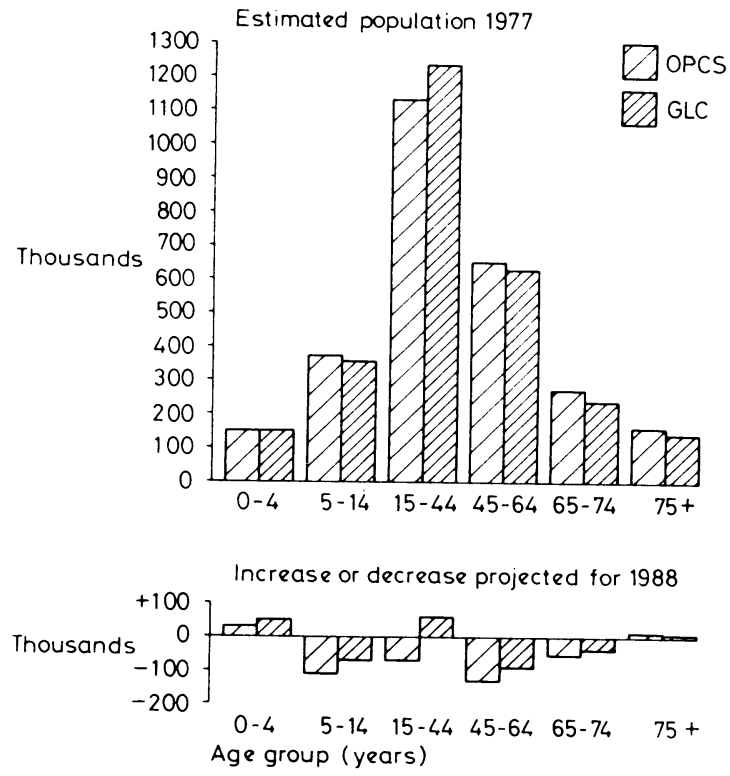

OPCS and GLC 1977 population estimates by age group, and projected changes for 1988, Inner London. (Changes projected by OPCS were 1977 based; those projected by GLC were 1980 based (assuming high fertility and low migration).)

TABLE I-Comparison of OPCS and GLC population projections by age group for Inner London (population in thousands)

\begin{tabular}{|c|c|c|c|c|c|c|c|}
\hline & All ages & $0-4$ & $5-14$ & $15-44$ & $45-64$ & $65-74$ & $75+$ \\
\hline $\begin{array}{l}\text { OPCS (1977 based) } \\
\text { GLC (1980 based })\end{array}$ & $\begin{array}{l}2728 \\
2743\end{array}$ & $\begin{array}{l}151 \\
156\end{array}$ & $\begin{array}{l}1977 \\
370 \\
351\end{array}$ & $\begin{array}{l}1127 \\
1213\end{array}$ & $\begin{array}{l}652 \\
633\end{array}$ & $\begin{array}{l}269 \\
247\end{array}$ & $\begin{array}{l}159 \\
143\end{array}$ \\
\hline $\begin{array}{l}\text { OPCS }(1977 \text { based }) \\
\text { GLC } 1 \text { (1980 based }) \\
\text { GLC } 4 \text { (1980 based }\end{array}$ & $\begin{array}{l}2387 \\
2653 \\
2491\end{array}$ & $\begin{array}{l}178 \\
201 \\
167\end{array}$ & $\begin{array}{c}1988 \\
256 \\
285 \\
263\end{array}$ & $\begin{array}{l}1056 \\
1294 \\
1217\end{array}$ & $\begin{array}{l}516 \\
527 \\
510\end{array}$ & $\begin{array}{l}212 \\
199 \\
193\end{array}$ & $\begin{array}{l}169 \\
146 \\
142\end{array}$ \\
\hline
\end{tabular}

GLC 1 assumes high fertility and low migration loss. GICC 4 assumes low fertility and high migration loss. 
TABLE II-Effects of varying 1988 population assumptions on LHPC projected bed requirements (acute hospital beds)

\begin{tabular}{|c|c|c|c|c|c|c|c|c|c|c|c|c|c|}
\hline \multirow[b]{2}{*}{ District } & & & & & & & \multicolumn{4}{|c|}{ Regional specialties } & \multicolumn{3}{|c|}{ Non-regional specialties } \\
\hline & & & & & & & & $\begin{array}{l}\text { LHPC } \\
\text { projected beds }\end{array}$ & $\begin{array}{c}0_{0} \text { change } \\
\text { using GLC }\end{array}$ & $\begin{array}{c}\% \text { change } \\
\text { using GLC } 4\end{array}$ & $\begin{array}{c}\text { LHPC } \\
\text { projected beds }\end{array}$ & $\begin{array}{c}\% \text { change } \\
\text { using GLC } 1\end{array}$ & $\begin{array}{c}\% \text { change } \\
\text { using GLC } 4\end{array}$ \\
\hline Bedfordshire & . & . & .. & . & . & . & . & 0 & - & - & 1062 & 0 & 0 \\
\hline Hertfordshire & .. & . & .. & . & . & . & . & 2 & 0 & 0 & 1859 & -0.2 & -0.3 \\
\hline Barnet $\quad \ldots$ & .. & .. & . & . & . & . & . & 0 & - & - & 338 & $-2 \cdot 1$ & $-4 \cdot 4$ \\
\hline Edgware .. & . & . & . & . & . & . & . & 30 & $+3 \cdot 3$ & 0 & 406 & $-2 \cdot 5$ & $-6 \cdot 7$ \\
\hline Brent & . & .. & .. & . & . & . & . & 42 & $-7 \cdot 1$ & $-9 \cdot 5$ & 392 & +3.6 & $-1 \cdot 3$ \\
\hline Harrow $\quad$. & $\ldots$ & .. & .. & $\ldots$ & . & .. & .. & 0 & - & - & 516 & $-3 \cdot 7$ & $-8 \cdot 0$ \\
\hline Hounslow & .. & .. & . & . & .. & .. & .. & 16 & $+6 \cdot 3$ & 0 & 514 & +0.2 & $-3 \cdot 3$ \\
\hline \multirow{2}{*}{\multicolumn{2}{|c|}{$\begin{array}{l}\text { South Hammersmith } \\
\text { North Hammersmith }\end{array}$}} & .. & .. & .. & $\ldots$ & $\ldots$ & .. & 119 & $+1 \cdot 7$ & $-0: 8$ & 497 & +7.8 & $+3 \cdot 4$ \\
\hline & & $\ldots$ & .. & .. & .. & .. & . & 129 & +0.8 & $-0 \cdot 8$ & 315 & $+4 \cdot 1$ & 0 \\
\hline Ealing $\quad \ldots$ & . & . & . & . & .. & . & . & 0 & - & - & 395 & -0.5 & $-5 \cdot 3$ \\
\hline Hillingdon & .. & . & . & . & . & . & . & 296 & $+0 \cdot 7$ & $-0 \cdot 7$ & 651 & -2.5 & $-4 \cdot 6$ \\
\hline \multicolumn{7}{|c|}{ Kensington, Chelsea and Westminster (north west) .. } & . & 62 & 0 & 0 & 687 & +1.6 & -1.5 \\
\hline \multicolumn{7}{|c|}{ Kensington, Chelsea and Westminster (north east) ... } & .. & 194 & $-1 \cdot 0$ & $-2 \cdot 6$ & 438 & +0.7 & $-2 \cdot 3$ \\
\hline \multicolumn{7}{|c|}{ Kensington, Chelsea and Westminster (south) } & . & 88 & 0 & $-1 \cdot 1$ & 688 & +1.9 & -1.5 \\
\hline Essex & . & .. & . & . & . & . & . & 184 & +0.5 & 0 & 3653 & -0.3 & -0.6 \\
\hline Barking $\quad$. & . & .. & . & . & . & . & .. & 56 & 0 & $-3 \cdot 6$ & 620 & $-2 \cdot 7$ & $-5 \cdot 9$ \\
\hline Havering .. & .. & .. & .. & .. & .. & .. & .. & 0 & - & - & 378 & $-2 \cdot 4$ & $-4 \cdot 0$ \\
\hline North Camden & .. & .. & .. & . & .. & .. & . & 101 & 0 & $-3 \cdot 0$ & 528 & +0.8 & $-3 \cdot 2$ \\
\hline South Camden & .. & $\ldots$ & .. & $\ldots$ & $\ldots$ & $\ldots$ & . & 84 & $-1 \cdot 2$ & $-3 \cdot 6$ & 529 & +0.2 & $-2 \cdot 8$ \\
\hline Islington .. & . & .. & .. & . & . & . & . & 44 & $+4 \cdot 5$ & 0 & 578 & $+4 \cdot 0$ & -0.9 \\
\hline City $\quad \ldots$ & . & . & . & . & . & . & . & 292 & -0.3 & -0.7 & 864 & $+2 \cdot 1$ & $-1 \cdot 2$ \\
\hline Newham .. & .. & $\ldots$ & .. & . & . & . & . & 0 & - & - & 475 & $-2 \cdot 3$ & $-6 \cdot 1$ \\
\hline Tower Hamlets & $\ldots$ & .. & . & $\ldots$ & . & .. & . & 158 & 0 & $-3 \cdot 2$ & 747 & +0.1 & $-2 \cdot 8$ \\
\hline Enfield $\quad .$. & . & . & .. & .. & . & .. & .. & 11 & 0 & 0 & 500 & +0.6 & -0.8 \\
\hline Haringey ... & . & . & . & $\ldots$ & $\ldots$ & $\ldots$ & $\ldots$ & 30 & 0 & 0 & 597 & $+2 \cdot 0$ & $-1 \cdot 3$ \\
\hline East Roding & .. & .. & .. & .. & . & .. & .. & 3 & 0 & 0 & 383 & $-7 \cdot 3$ & $-10 \cdot 0$ \\
\hline West Roding & $\ldots$ & . & .. & . & . & . & . & 18 & $+5 \cdot 6$ & 0 & 712 & $+2 \cdot 4$ & $-1 \cdot 0$ \\
\hline East Sussex & .. & .. & .. & $\ldots$ & . & .. & .. & 85 & 0 & 0 & 1694 & 0 & 0 \\
\hline Kent $\quad$. & .. & .. & .. & . & . & . & . & 219 & +0.5 & 0 & 3794 & -0.1 & $-0 \cdot 2$ \\
\hline Bexley & . & . & .. & $\ldots$ & . & .. & . & 0 & - & - & 345 & -1.4 & $-4 \cdot 6$ \\
\hline Greenwich & . & . & . & . & .. & . & . & 150 & $+2 \cdot 0$ & $+1 \cdot 3$ & 808 & $+2 \cdot 6$ & $-3 \cdot 0$ \\
\hline Bromley $\quad$. & . & . & . & . & . & $\ldots$ & $\ldots$ & 14 & 0 & 0 & 577 & $+1 \cdot 0$ & $-1 \cdot 4$ \\
\hline St Thomas's & . & $\ldots$ & . & . & . & . & . & 100 & $+1 \cdot 0$ & 0 & 612 & $+2 \cdot 1$ & -1.5 \\
\hline King's & . & $\ldots$ & .. & $\ldots$ & $\ldots$ & . & $\ldots$ & 123 & $+4 \cdot 1$ & 0 & 683 & $+5 \cdot 9$ & $-1 \cdot 2$ \\
\hline Guy's & .. & .. & .. & .. & . & .. & .. & 156 & $+2 \cdot 0$ & 0 & 658 & $+7 \cdot 1$ & -0.3 \\
\hline Lewisham & $\ldots$ & . & . & . & . & .. & . & 2 & 0 & 0 & 493 & $+2 \cdot 6$ & $-3 \cdot 2$ \\
\hline Surrey $\quad$. & .. & .. & .. & .. & . & .. & .. & 191 & 0 & 0 & 2721 & 0 & $-0 \cdot 1$ \\
\hline West Sussex & .. & .. & .. & .. & $\ldots$ & .. & .. & 62 & +1.6 & $+1 \cdot 6$ & 1506 & -0.1 & -0.1 \\
\hline Croydon .. & . & .. & .. & .. & . & .. & .. & 14 & 0 & 0 & 577 & $-3 \cdot 3$ & $-5 \cdot 9$ \\
\hline Kingston .. & . & $\ldots$ & .. & . & . & .. & $\ldots$ & 0 & - & - & 509 & -3.9 & -6.5 \\
\hline Roehampton & $\ldots$ & $\ldots$ & .. & .. & .. & .. & . & 96 & $+2 \cdot 1$ & 0 & 277 & +1.4 & $-2 \cdot 2$ \\
\hline East Merton & .. & .. & .. & .. & $\ldots$ & .. & $\ldots$ & 182 & $+2 \cdot 1$ & $-2 \cdot 2$ & 899 & $+1 \cdot 1$ & $-3 \cdot 0$ \\
\hline West Merton & .. & . & $\ldots$ & . & . & .. & . & 21 & 0 & $-4 \cdot 8$ & 712 & -1.5 & $-5 \cdot 5$ \\
\hline
\end{tabular}

GLC 1 assumes high fertility and low migration (1980 based). GLC 4 assumes low fertility and high migration (1980 based). LHPC projections assume OPCS 1977 -based population projections for 1988. Regional specialties consist of neurology, cardiology, radiotherapy, thoracic surgery, neurosurgery, plastic surgery, and other specialist units (acute only, as per SH3).

If the GLC projection 1 were valid the net loss from Inner London would be $3.4 \%$ and not $12.5 \%$. The age structures of the two projections are different, however, with OPCS suggesting a more aged population for 1988. Thus, though the GLC projection for total population is higher, it includes fewer people in the older age groups (who are higher users of the health services). Consequently, the changes in bed provision that arise from the replacement of OPCS projection with GLC projections are smaller than is suggested by a crude comparison of total projection populations. The projected bed requirements using OPCS's 1977-based projections and using 1980-based GLC projections 1 (high fertility, low migration) and 4 (low fertility, high migration) are given in table II.

Although the different population assumptions do not make a great deal of difference to the Thames regions collectively, they do make quite considerable differences to some districts. The migration assumptions OPCS will use for the 1979-based population projections assume a net loss for Inner London that is about 100000 less than the 1977-based series assumes (personal communication, GLC Population Studies Section, 1980). The main differences will be in the middle and under-5 age groups, which are the groups most likely to move. This would imply a fall in Inner London population of $8.4 \%$ by 1988 , as opposed to $12.5 \%$ previously projected. The detailed breakdown by age and smaller areas is not yet available so could not be incorporated in the sensitivity analysis above. In view of the uncertainty surrounding the actual future values of particular data or their statistical reliability, bed planning should attempt to be as flexible as possible so that acute facilities are not irrevocably closed down where they may be needed.

I am grateful to Professor W W Holland for suggesting the topic, J Knight of the South-east Thames Regional Health Authority for running the model under various assumptions, the DHSS for supplying the data in table II, Miss M Eames and Miss R Khair for extracting data from published material and computer printouts, and Dr Peter West for his helpful comments.

\section{References}

${ }^{1}$ London Health Planning Consortium. Towards a balance: a framework for acute hospital services in London, reconciling service with teaching needs. London: LHPC, 1980.

2 London Health Planning Consortium. Acute hospital services in London: a profile. London: HMSO, 1980.

${ }^{3}$ Rosenhead J. Planning under uncertainty: I. The inflexibility of methodologies. Fournal of the Operational Research Society 1980;31:209-16.

4 Rosenhead J. Planning under uncertainty: II. A methodology for robustness analysis. Fournal of the Operational Research Society 1980 ;31:331-41.

${ }^{5}$ Royal Commission on the National Health Service. Management of financial resources in the NHS. Research paper No 2. London: HMSO, 1978.

${ }^{6}$ Campbell R. Population projections: English regions and counties. Population Trends 1979;16:17-21.

${ }^{7}$ Hollis J, Condon P. 1980 round demographic projections for Greater London. London: GLC Statistical Series 2, 1980.

(Accepted 15 fanuary 1981) 